\title{
Potensi Keuntungan Kompetitif Penggunaan Internet Bagi Perusahaan
}

\author{
Donny Fernando, SKom, MM \\ Jurusan Sistem Informasi Fakultas Teknologi Informasi Universitas Serang Raya \\ Jln. Raya Cilegon Serang - Drangong Kota Serang \\ donnyfernando@unsera.ac.id
}

\begin{abstract}
Perkembangan pembangunan infrastruktur ICT, dukungan regulasi pemerintah serta biaya koneksi yang relatif terjangkau mendorong pelaku bisnis untuk dapat berkompetisi secara global. Makalah ini bertujuan untuk mengkaji beberapa faktor yang mempengaruhi perusahaan untuk mendapatkan keuntungan kompetitif terhadap penggunaan internet. Adapun tujuan penelitian ini dilakukan adalah untuk melakukan identifikasi faktor-faktor yang mendatangkan dan meningkatkan keuntungan kompetitif bagi perusahaan dalam mentransformasikan strategi bisnisnya dengan media Internet dan mendapatkan suatu model statistik yang dapat dikembangkan menjadi sebuah model bagi perusahaan yang akan mentransformasikan Internet kedalam strategi bisnisnya. Untuk melakukan penelitian ini penulis menggunakan metode deskriptif.

Kata kunci - internet, e-businness, marketing, strategi bisnis, perilaku pelanggan, pangsa pasar, pendapatan perusahaan
\end{abstract}

\section{PENDAhUluan}

APJII (Asosiasi Penyelenggara Jasa Internet Indonesia) telah mengumumkan hasil survei Data Statistik Pengguna Internet Indonesia tahun 2016.

Jumlah pengguna Internet di Indonesia tahun 2016 adalah 132,7 juta user atau sekitar $51,5 \%$ dari total jumlah penduduk Indonesia sebesar 256,2 juta.

Kemunculan internet telah menjadi tema besar dalam mewujudkan demokrasi digital (Coleman 2006). Internet telah memudahkan jalan untuk mengakses informasi semudah dan secepat mungkin dari berbagai sumber.

Jumlah masyarakat kelas menengah masih mendominasi di Indonesia. Angka pertumbuhan penduduk yang terus meningkat tiap tahunpun menambah jumlah masyarakat kelas menengah tersebut. Sebuah penelitian bernama The Boston Consulting Group memprediksikan di tahun 2020, jumlah populasi kelas menengah di Indonesia diperkirakan mencapai 141 juta jiwa.

Pada bidang perekonomian negara, masyarakat kelas menengah memiliki peranan penting. Kelompok tersebut memiliki angka produktifitas dan konsumsi yang relatif tinggi. Kelompok masyarakat kelas menengah di berbagai negara mempunyai potensi untuk mengangkat roda perekonomian di suatu negara.

\section{Metodologi Penelitian}

Pada tahapan awal penulis melakukan pengumpulan aspek-aspek yang mempengaruhi keberhasilan perusahaan dalam memanfaatkan internet dalam strategi bisnisnya. Selanjutnya penulis mengambil sample perusahaan yang akan digunakan untuk penelitian ini. Agar hasil analisa mempunyai validitas yang tinggi maka penulis memilih untuk mengambil sampel dari perusahaan yang mempunya model bisnis yang sejenis. Dari 150 perusahaan yang dikumpulkan, penulis memilih 100 perusahaan yang akan digunakan sebagai bahan penelitian.
Selanjutnya penulis mengembangkan kuisioner yang dikembangkan sesuai dengan model penelitian yang diuji. Pada penelitian ini penulis menerapkan model strategi pemanfaatan internet bagi perusahaan dengan model sbb:

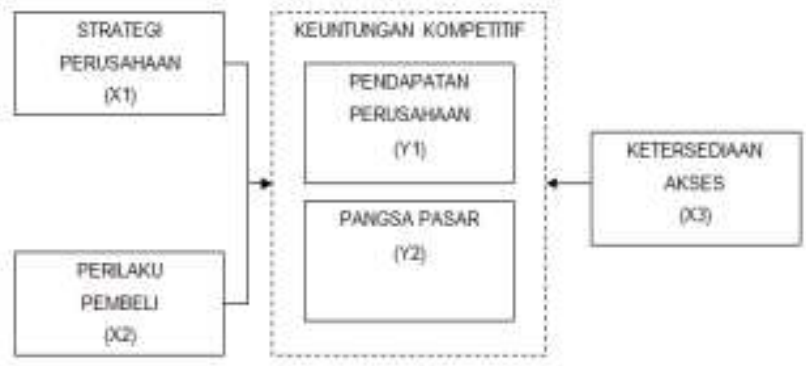

Gambar 1. Model Penelitian.

Keterangan rinci mengenai variable-variable diatas dapat dijelaskan di bawah ini

X1 = Strategi Perusahaan, diwakilkan dengan variable A pada perhitungan penelitian ini, meliputi perencanaan perusahaan dan ketersediaan sumberdaya perusahaan.

X2 = Perilaku Pelangan, diwakilkan dengan variable B pada perhitungan penelitian ini, meliputi kebiasaan dan budaya dari calon pelanggan, pelanggan dan pelanggan baru.

X3 = Ketersediaan Akses, diwakilkan dengan variable $\mathrm{C}$ pada perhitungan penelitian ini, meliputi akses internet yang dimiliki calon pelanggan, pelanggan dan pelanggan baru.

Y1 = Pangsa Pasar, diwakilkan dengan variable D pada perhitungan penelitian ini, meliputi perluasan pasar dan potensi mendapatkan pasar yang baru.

Y2 = Pendapatan Perusahaan, diwakilkan dengan variable $E$ pada perhitungan penelitian ini, meliputi pendapatan perusahaan mengalami peningkatan atau penurunan akibat pemanfaatan internet ini. 
Untuk menjaga keabsahan data dan hasil analisa untuk mendukung teori dan hipotesa yang diambil maka penulis melakukan uji validitas.

Agar suatu fakta mempunyai ketergantungan dan konsistensi dengan hal yang lain, sehingga bukan hanya menjadi suatu teori atau hal yang tidak dapat dipertanggungjawabkan maka penulis melakukan Uji Reliabilitas.

Dalam penelitian ini terdapat 2 (dua) jenis variabel yaitu variabel bebas (independent variable) dan variabel tidak bebas (dependent variable). Variabel bebas dan variabel tak bebas memiliki nilai ordinal dengan keterangan sebagai berikut:

- $\quad$ Sangat Setuju (nilai ordinal $=1$ )

- Setuju (nilai ordinal $=2$ )

- Netral (nilai ordinal $=3$ )

- Tidak Setuju (nilai ordinal $=4$ )

- $\quad$ Sangat Tidak Setuju (nilai ordinal $=5$ )

Dalam penelitian ini digunakan metode multiple regression (regresi berganda) untuk mempelajari arah pengaruh dari satu atau lebih variable independent terhadap satu atau lebih variable dependent.

\section{HASIL DAN PEMBAHASAN}

Dari 100 kuisioner yang disebar, ada sebanyak 29 kuisioner yang tidak dapat dikirim karena kesalahan alamat. Kuisioner yang terkumpul adalah sebanyak 45 kuisioner. Jadi terdapat 26 kuisioner yang tidak dikembalikan oleh responden.

Dari 45 kuisioner yang dikembalikan, semuanya dapat dijadikan bahan untuk penelitian ini, karena tidak terdapat kuisioner yang tidak dapat digunakan dikarenakan tidak terisi secara lengkap. Kuisioner yang kembali diisi oleh berbagai responden dari jenis kelamin, usia, tingkat pendidikan, jabatan, ukuran perusahaan, kepemilikan divisi IT, dan jenis bidang usaha yang berbeda-beda.

Adapun variabel bebas yang di lakukan uji validitas dan uji reliabilitas pada penelitian ini adalah sebagai berikut:

- Faktor Strategi Bisnis Perusahaan diwakili dengan variabel X1

- Faktor Perilaku Pembeli diwakili dengan variabel X2

- Faktor Ketersediaan Akses diwakili dengan variabel X3

Sedangkan variabel terikat yang dilakukan uji validitas dan uji reliabilitas pada penelitian ini adalah sebagai berikut:

- Faktor Pangsa Pasar Perusahaan diwakili dengan variabel Y2

- Faktor Pendapatan Perusahaan diwakili dengan variabel Y1
Faktor Strategi Bisnis (X1) terlebih dulu dilakukan uji validitas untuk mengetahui level validitasnya. Dari hasil pengujian maka didapatkan nilai Alpha adalah $0.8163(>0.7)$ dengan semua item memiliki nilai $\mathrm{r}$ yang lebih besar dari 0.2483 .

Hasil pengujian Faktor Perilaku Pelanggan (X2) didapatkan nilai Alpha adalah $0.8208(>0.7)$ dengan semua item memiliki nilai r yang lebih besar dari 0.2483 .

Faktor Ketersediaan Akses (X3) dilakukan uji validitas maka didapatkan nilai Alpha adalah 0.8033 (>0.7) dengan semua item memiliki nilai $r$ yang lebih besar dari 0.2483

Faktor Pangsa Pasar (Y2) dilakukan uji validitas maka didapatkan nilai Alpha adalah 0.8047 (>0.7) dengan semua item memiliki nilai $r$ yang lebih besar dari 0.2483

Faktor Pendapatan (Y1) dilakukan uji validitas maka didapatkan nilai Alpha adalah 0.7680 (>0.7) dengan semua item memiliki nilai $r$ yang lebih besar dari 0.2483 .

Berdasarkan hasil uji validitas ini maka hal ini berarti semua item adalah valid dan reliable serta dapat digunakan untuk proses perhitungan selanjutnya dalam penelitian ini.

Selanjutnya untuk menguji hipotesa yang dikembangkan pada penelitian ini maka dikembangkan 2 hipotesa yaitu:

Hipotesa 1:

H0: faktor strategi bisnis, perilaku pelanggan dan ketersediaan akses internet tidak ada pengaruh terhadap pangsa pasar perusahaan

H1: faktor strategi bisnis, perilaku pelanggan dan ketersediaan akses internet ada pengaruh terhadap pangsa pasar perusahaan

Hipotesa 2:

H0: faktor strategi bisnis, perilaku pelanggan dan ketersediaan akses internet tidak ada pengaruh terhadap pendapatan perusahaan

H1: faktor strategi bisnis, perilaku pelanggan dan ketersediaan akses internet ada pengaruh terhadap pendapatan perusahaan

Pada langkah selanjutnya untuk mendapatkan hasil dari hipotesa ini akan dilakukan uji hipotesa dengan menggunakan uji multiple regression.

Uji regresi dilakukan terhadap data kuisioner untuk mengetahui bahwa variable bebas mempengaruhi terhadap variable terikat. Pada sub-bab ini akan diketahui bahwa variable bebas yaitu strategi bisnis perusahaan (X1), perilaku pembeli (X2) dan ketersediaan akses (X3) memiliki pengaruh terhadap variabel terikat pangsa pasar perusahaan (Y2) dan pendapatan perusahaan (Y1).

Dalam uji regresi ini metode yang dipergunakan adalah metode enter, pada metode enter akan dimulai dengan memasukkan semua variabel bebas dalam persamaan.

Setelah dipilih variable bebas dalam metode enter, maka langkah selanjutnya adalah melakukan analisa model summary. Dengan model summary terlihat seberapa besar kontribusi dari setiap variable bebas yang diikutsertakan pada variable terikat. 
Model summary dapat dilihat pada Gambar.2 dibawah ini.

\begin{tabular}{|c|c|c|c|c|}
\hline Model & R & R Square & $\begin{array}{c}\text { Adjusted R } \\
\text { Square }\end{array}$ & $\begin{array}{c}\text { Std. Error of } \\
\text { the Estimate }\end{array}$ \\
\hline 1 & $0.702^{(\mathrm{a})}$ & 0.493 & 0.456 & 0.29392 \\
\hline
\end{tabular}

Gambar 2. Model Summary Variable X1,X2,X3 terhadap Variable Y2

Dari model summary gambar 2 diatas diperoleh $\mathrm{R}$ square $=0.493$ dengan arti sebanyak $49.3 \%$ model regresi dari variable terikat (pangsa pasar perusahaan) dapat dijelaskan oleh variable bebas. Sisanya $50.7 \%$ dijelaskan oleh variabel lain yang tidak diperhitungkan.

Sedangkan untuk melihat model summary terhadap variable E dapat dilihat pada Gambar 3. di bawah ini.

\begin{tabular}{|c|c|c|c|c|}
\hline Model & R & R Square & $\begin{array}{c}\text { Adjusted R } \\
\text { Square }\end{array}$ & $\begin{array}{c}\text { Std. Error of } \\
\text { the Estimate }\end{array}$ \\
\hline 1 & $0.665^{(\mathrm{a})}$ & 0.442 & 0.401 & 0.51607 \\
\hline
\end{tabular}

Gambar 3. Model Summary Variable X1,X2,X3 terhadap Variable Y1

Dari model summary gambar 3 diperoleh $\mathrm{R}$ square = 0.442 dengan arti sebanyak $44.2 \%$ model regresi dari variable terikat (pendapatan perusahaan) dapat dijelaskan oleh variable bebas. Sisanya 55.8\% dijelaskan oleh variabel lain yang tidak diperhitungkan.

Selanjutnya penulis melakukan Uji Anova untuk mendapatkan tingkat signifikat dari model regresi. Semua model regresi dapat diterima jika nilai Sig $<$ dari nilai $\mathrm{a}=$ 0.05 namun jika nilai $\mathrm{a}=0.05$ maka ditolak. Untuk uji Anova pada variable Pangsa Pasar Perusahaan (Y2) dapat dilihat pada gambar 4 .

\begin{tabular}{|c|l|c|c|c|c|c|}
\hline Model & & $\begin{array}{c}\text { Sum of } \\
\text { Squares }\end{array}$ & df & $\begin{array}{c}\text { Mean } \\
\text { Square }\end{array}$ & F & Sig- \\
\hline 1 & $\begin{array}{l}\text { Regressio } \\
\text { D }\end{array}$ & 3.441 & 3 & 1.147 & 13.227 & $000 \%$ \\
\hline & Residual & 3.542 & 41 & 0.086 & & \\
\hline & Total & 6.983 & 44 & & & \\
\hline
\end{tabular}

Gambar 4. ANOVA ${ }^{\mathrm{b}}$ Variable D

Dari gambar 4 terlihat nilai Sig. $=0<$ dari nilai a $=0.05$ sehingga model regresi layak digunakan, dengan kata lain terdapat hubungan linier antara variable bebas dengan variabel terikat pada penelitian ini.

\begin{tabular}{|c|l|c|c|c|c|c|}
\hline Model & & $\begin{array}{c}\text { Sum of } \\
\text { Squares }\end{array}$ & df & $\begin{array}{c}\text { Mean } \\
\text { Square }\end{array}$ & F & Sig. \\
\hline 1 & $\begin{array}{l}\text { Regressio } \\
\mathrm{n}\end{array}$ & 8.650 & 3 & 2.883 & 10.826 & $.000(*)$ \\
\hline & Residual & 10.919 & 41 & 0.266 & & \\
\hline & Total & 19.569 & 44 & & & \\
\hline
\end{tabular}

Gambar 5. ANOVA ${ }^{\mathrm{b}}$ Variable E
Dan dari gambar 5 terlihat nilai Sig. $=0<$ dari nilai a $=$ 0.05 sehingga model regresi layak digunakan, dengan kata lain terdapat hubungan linier antara variable bebas dengan variabel terikat pada penelitian ini.

Untuk koofisien masing-masing variable dapat dilihat pada gambar di bawah ini:

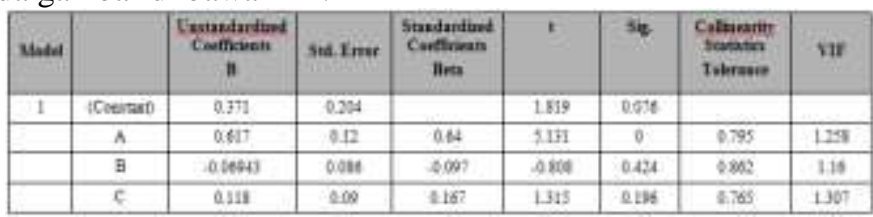

Gambar 6. Coefficients Regressions Variable Y2

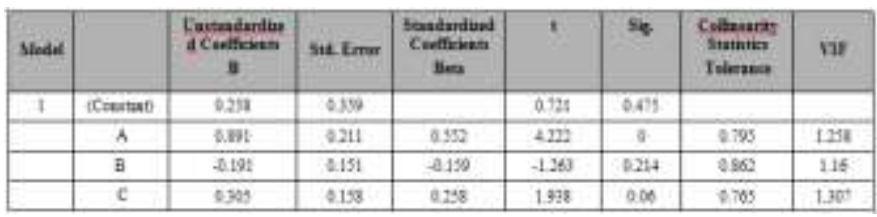

Gambar 7. Coefficients Regressions Variable Y1

Dari table koofisien gambar 6 dan gambar 7 dapat terlihat bahwa nilai Variance Infation Factor (VIF) lebih kecil dari 5 yang merupakan batas untuk memeriksa terjadinya kolineritas. Dengan nilai yang lebih kecil dari 5 maka variable diatas tidak terjadi kolineritas.

\section{KESIMPULAN}

Kesimpulan yang didapatkan dari hasil penelitian ini adalah:

1. Dari ketiga faktor bebas yang diuji pada penelitian ini memberikan pengaruh terhadap peningkatakan keuntungan kompetitif perusahaan namun tetap masih ada faktor lain yang dapat mempengaruhi keuntungan kompetitif perusahaan yang tidak diuji pada penelitian ini.

2. Dari ketiga faktor bebas yang di uji memberikan pengaruh $49,3 \%$ terhadap pangsa pasar perusahaan dan $44,2 \%$ untuk pengaruh terhadap pendapatan perusahaan.

3. Dari ketiga faktor bebas yang diuji, faktor strategi perusahaan memberikan pengaruh yang lebih kuat dibandingkan 2 faktor lainnya terhadap faktor pangsa pasar perusahaan dan pendapatan perusahaan.

4. Masih ada faktor-faktor lain yang mempengaruhi tingkat keuntungan kompetitif yang didapatkan perusahaan dalam menggunakan internet dalam strategi bisnisnya.

5. Dari hasil penelitian ini dapat disimpulkan bahwa pada ketiga faktor bebas dan kedua faktor terikat tersebut ada hubungan yang sangat kuat, significant dan searah. Dengan kata lain, jika ketiga faktor tersebut meningkat positif maka faktor terikat akan semakin meningkat. 


\section{UCAPAN TERIMA KASIH}

Bagian ini memberikan apresiasi kepada perorangan maupun organisasi yang memberikan bantuan kepada penulis. Ucapan terima kasih kepada pihak sponsor maupun dukungan finansial juga dituliskan di bagian ini.

\section{REFERENSI}

[1] N.F Doherty, F. Ellis-Chadwick and C.A. Hart, 1999, Cyber Retailing In UK: The Potential Of The Internet As A Retail Channel, International Journal of Retail \& Distribution Management Volume 27

[2] Ruby Roy Dholakia and Outi Uusitalo, 2002, Switching To Electronic Strores: Consumer Characteristics And The Perception Of Shopping Benefits, International Journal of Retail \& Distribution Management Volume 30

[3] Zhilin Yang, 2003, Customers' perception of online retailing service quality and their satisfaction, International Journal of Quality \& Reliablity Management Volume 21
[4] Adam S Huarng and Doris Christopher, 2003, Planning an effective Internet retail store, International Journal of Retail \& Distribution Management

[5] Johar Arifin, 2007, Statistik Bisnis Terapan dengan Microsoft Excel 2007, Elex Media Komputindo

[6] Jonathan Sarwono dan Tutty Martadiredja, 2008, Riset Bisnis untuk Pengambilan Keputusan, Andi Offset

[7] Yuni Prihadi Utomo, 2007, Eksplorasi Data dan Analisa Regresi dengan SPSS, Muhammadiyah University Press

[8] Tawfik Jelassi and Albrecht Enders, 2007, Strategies for e-Business Creating Value through Electronic and Mobile Commerce, Prentice Hall

[9] Philip Kotler and Kevin Lane Keller, 2006, Marketing Management 12 Edition, Pearson International Edition

[10] Dave Chaffey, 2008, E-business and E-commerce Management, Prentice Hall Third EditionS. M. Metev and V. P. Veiko, Laser Assisted Microtechnology, 2nd ed., R. M. Osgood, Jr., Ed. Berlin, Germany: Springer-Verlag, 1998. 